\title{
Quality of Life of Patients with Knee Osteoarthritis with Questionnaire OAKHQOL (OsteoArthritis of Knee Hip Quality of Life) in Rheumatology Consultation in Burkina Faso (West Africa)
}

\author{
Dieu-Donné Ouédraogo ${ }^{*}$, Joelle Tiendrébéogo/Zabsonré1, Aimé Davy Sèvy Kenagnon ${ }^{1}$ \\ Fulgence Kaboré1, Christian Compaoré ${ }^{2}$, Youssouf Joseph Drabo ${ }^{3}$, Xavier Chevalier ${ }^{4}$ \\ ${ }^{1}$ Department of Rheumatology, Yalgado Ouedraogo University Hospital, Ouagadougou, Burkina Faso \\ ${ }^{2}$ Rheumatology Unit, International Polyclinic of Ouagadougou, Ouagadougou, Burkina Faso \\ ${ }^{3}$ Department of Internal Medicine, Yalgado Ouedraogo University Hospital, Ouagadougou, Burkina Faso \\ ${ }^{4}$ Department of Rheumatology, Henri Mondor University Hospital, Paris, France \\ Email: *ouedd@yahoo.fr
}

Received 27 August 2014; revised 27 September 2014; accepted 27 October 2014

Copyright (C) 2014 by authors and Scientific Research Publishing Inc.

This work is licensed under the Creative Commons Attribution International License (CC BY).

http://creativecommons.org/licenses/by/4.0/

(c) (i) Open Access

\section{Abstract}

Objective: To study the quality of life of patients with knee OA with the questionnaire OAKHQOL (OsteoArthritis of Knee Hip Quality Of Life). Patients and Methods: This was a cross-sectional study over a period of six months, in patients with symptomatic knee osteoarthritis. All patients met the clinical and radiological criteria of the ACR. The OAKHQOL questionnaire was used to investigate the quality of life of patients. Results: One hundred and six patients were included. There were $94(88.7 \%)$ women and $12(11.3 \%)$ men with a sex ratio of 0.12 . The average age of patients was $55 \pm 10.4$ years. The average pain intensity was $55.1 \pm 22.4$. The majority of patients (69.8\%) had stage 3 of Kellgren and Lawrence classification. The dimension "pain" had the lowest normalized score $(60.6)$. There was a significant correlation between the age range of 30 to 40 years and declining mental health (49.5). The patients with over 60 years of age had a decrease in pain tolerance and reduced social activities. Lequesne score was associated with severe all dimensions except "social support" of the patient. Conclusion: The knee has an impact on quality of life of patients followed in rheumatology by OAKHQOL questionnaire.

\footnotetext{
${ }^{*}$ Corresponding author.
} 


\section{Keywords}

\section{Quality of Life, Osteoarthritis, Knee, Psychometrics, Africa}

\section{Introduction}

OsteoArthritis of Knee affects $12.1 \%$ of the adult population in the United States [1]. This is a common disease with significant functional impairment, impaired quality of life for the patient and a social cost [1] [2]. It is the second reason for consultation in rheumatology in Saharan Africa and the first location of osteoarthritis in the lower limbs [3]-[8]. Its functional impact is important and appreciated by several scores; the most used ones are the Lequesne score and WOMAC [9]-[11]. Thus, a Lequesne index average of 14.5 or a WOMAC index of 51.3 is an indication for knee arthroplasty [12].

Existing instruments focus on symptoms and function without taking into account many other aspects of the impact of the disease perceived by the patient including the quality of life and the psyche of the patient. Several scales have been developed and validated. Among these, only the Arthritis Impact Measurement Scales (AIMS2) and short (AIMS2-SF) [13] [14] and the questionnaire OAKHQOL (OsteoArthritis of Knee Hip Quality of Life) allow the understanding of the social components of the disease [15] [16]; OAKHQOL questionnaire showed that the quality of life of patients with osteoarthritis of the knee or hip was altered in several of its components [17]. Knee osteoarthritis is considered more common in black African woman [18]. However, few studies have been conducted on the quality of life in these patients with OAKHQOL questionnaire. The purpose of this study was to assess the quality of life of patients with knee osteoarthritis in a black African population.

\section{Patients and Methods}

This was a cross-sectional study from January 2013 to June 2013 who concerned all patients received during the study period for symptomatic knee osteoarthritis in Rheumatology consultation at the University Hospital Yalgado Ouedraogo Ouagadougou, Burkina Faso. All patients included in the study met the clinical and radiological criteria of the ACR [19]. They all received a complete clinical examination by the same rheumatologists (ODD and ZTJ). The blood-cell count, erythrocyte sedimentation rate and C reactive protein (CRP) were systematic. Radiography of both knees was performed, incidence face load, schuss, in profile and axial effects at 30 and 60.

Data were collected on a pre-computerized record containing the socio-demographic and anthropometric parame ters, functional signs, physical and radiographic, the algo-functional index (visual analogy scale, Lequesne index) and scale OAKHQOL. The variables were then analyzed using the Epi-info version 7.0. ANOVA and Fisher's exact test were used for statistical analysis. A probability $\mathrm{p}<0.05$ was considered statistically significant.

\section{Results}

\subsection{General Characteristics of Patients}

One hundred and six patients were recruited during the study period. There were 94 (88.7\%) women and 12 (11.3\%) men with a sex ratio of 0.12 .

The average age of patients was $55 \pm 10.4$ with extremes of 31 and 80 years. The average age of women was $54.1 \pm 10.0$ years; for men it was $61.7 \pm 12.2$ years $(\mathrm{p}<0.05)$. Figure 1 shows the distribution of patients by age group.

The mean BMI of our patients was $30.9 \pm 6.5 \mathrm{~kg} / \mathrm{m}^{2}$ with a range of 15.8 to $45.4 \mathrm{~kg} / \mathrm{m}^{2}$. Among the 94 women, 62 (66.0\%) were postmenopausal with a mean duration of menopause $10.3 \pm 7.9$ years. Twenty-five (23.6\%) patients had a history of knee trauma, 39 (36.8\%), arterial hypertension and 10 (9.4\%) diabetes mellitus.

The average intensity of knee pain according to VAS was 55.5/100 \pm 22.4 with extremes of 10 and 100. Sixty-seven patients (63.2\%) had joint stiffness. The average duration of joint stiffness was $2.8 \pm 7.6$ minutes with a range of 1 to 60 minutes. Architectural defects were observed in $39.6 \%$ of patients. Table 1 shows the distribu- 
tion of patients according to clinical data.

Radiographically, 74 patients (69.8\%) had stage 3 of Kellgren and Lawrence. Table 2 shows the distribution of patients according to radiographic data.

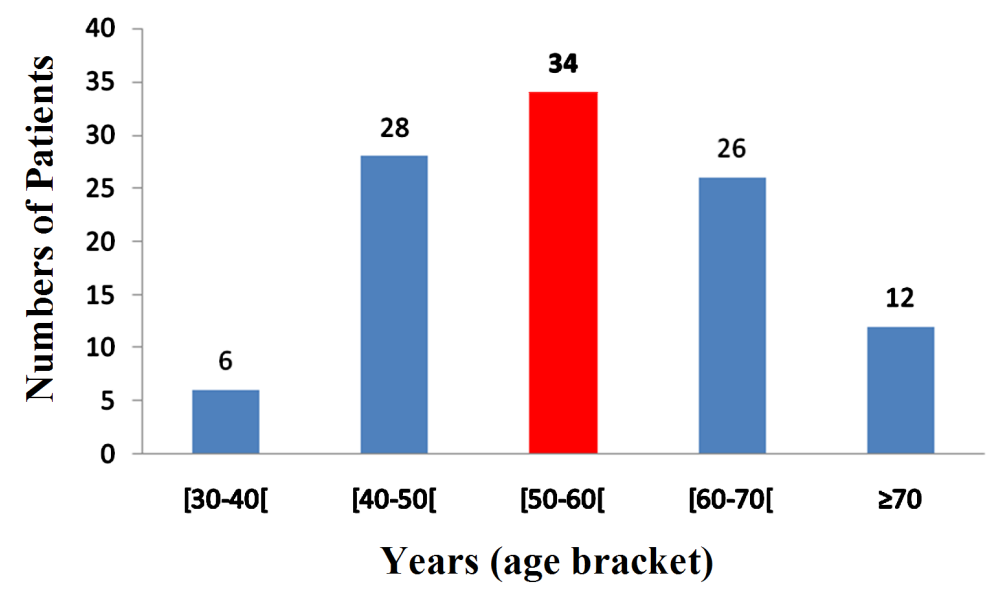

Figure 1. Distribution of patients by age group.

Table 1. Distribution of patients according to clinical data.

\begin{tabular}{|c|c|c|}
\hline & Frequency & Percentage \\
\hline \multicolumn{3}{|l|}{ Knee Pain $(n=106)$} \\
\hline Bilateral & 67 & 63.2 \\
\hline Left & 20 & 18.9 \\
\hline Right & 19 & 17.9 \\
\hline \multicolumn{3}{|l|}{ Joint Stiffness $(n=106)$} \\
\hline Yes & 67 & 63.2 \\
\hline No & 39 & 36.8 \\
\hline \multicolumn{3}{|l|}{ Architectural Defects $(n=106)$} \\
\hline Absence of Static Disorder & 64 & 60.4 \\
\hline Genu Valgum Unilateral & 12 & 11.3 \\
\hline Genu Valgum Bilateral & 10 & 9.4 \\
\hline Genu Varum Bilateral & 8 & 7.5 \\
\hline Genu Varum Unilateral & 6 & 5.7 \\
\hline Genu Flexum Unilateral & 4 & 3.8 \\
\hline Genu Flexum Bilateral & 1 & 0.9 \\
\hline Genu Recurvatum Unilateral & 1 & 0.9 \\
\hline \multicolumn{3}{|l|}{ Crunch $(n=106)$} \\
\hline Yes & 59 & 55.7 \\
\hline No & 47 & 44.3 \\
\hline \multicolumn{3}{|l|}{ Joint Limitation $(n=106)$} \\
\hline Yes & 24 & 22.6 \\
\hline No & 82 & 77.4 \\
\hline
\end{tabular}




\subsection{Description of the Impact of Knee Osteoarthritis}

\subsubsection{Impact on Function by the Lequesne Index}

Lequesne average score was $9.1 \pm 3.6$ with a range of 0 to 18 . Sixty-seven patients (63.2\%) had a score of Lequesne than or equal to 8. Figure 2 shows the distribution of patients according to the Lequesne score.

\subsubsection{Sounding Psycho-Social Scale by OAKHQOL}

The "pain" dimension had the lowest normalized score (60.6). Table 3 shows the standardized scores of OAKHQOL means and standard deviation. They ranged from 9.4 to 99.4 for physical activity, 4.6 to 98.5 for mental health varies from 0 to 100 for pain and 20.0 to 100 social support.

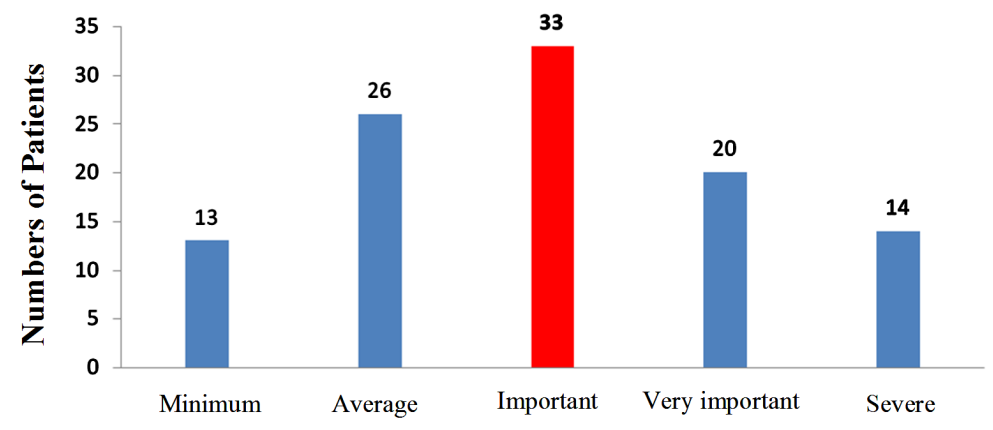

Lequesne Score

Figure 2. Distribution of patients according to the Lequesne score.

Table 2. Distribution of patients according to radiographic data.

\begin{tabular}{|c|c|c|}
\hline & Frequency & Percentage \\
\hline \multicolumn{3}{|c|}{ Kellgren and Lawrence Classification $(n=106)$} \\
\hline Stage 0 & 2 & 1.9 \\
\hline Stage 1 & 0 & 0 \\
\hline Stage 2 & 0 & 0 \\
\hline Stage 3 & 74 & 69.8 \\
\hline Stage 4 & 30 & 28.3 \\
\hline \multicolumn{3}{|c|}{ Osteoarthritis of Knee $(n=106)$} \\
\hline Unicompartmental & 20 & 18.9 \\
\hline Bicompartmental & 54 & 50.9 \\
\hline Tricompartimental & 32 & 30.2 \\
\hline
\end{tabular}

Table 3. Means and standard deviations of the standardized questionnaire scores OAKHQOL.

\begin{tabular}{cccc}
\hline & Number of Items & Average Standardized Score & Standard Deviation \\
\hline Physical Activity & 16 & 62.6 & 17.3 \\
Mental Health & 13 & 66.8 & 18.7 \\
Pain & 4 & $\mathbf{6 0 . 6}$ & $\mathbf{2 0 . 0}$ \\
Social Support & 4 & 75.6 & 20.1 \\
Social Activities & 3 & 75.6 & 22.7 \\
\hline
\end{tabular}




\subsection{Influence of Different Variables on the Quality of Life}

The young age (30 - 40 years) was statistically associated with the "Mental Health" (49.5) while the dimension above 60 years of age alters the quality of life in the dimensions of pain and social activities. Static disorders including genu-flessum affect the quality of life in all dimensions of the questionnaire OAKHQOL while a severe Lequesne score was associated with all dimensions except the dimension of social support to the patient. Table 4 shows the distribution of standardized questionnaire OAKHQOL according to patient characteristics scores.

\section{Discussion}

This is to our knowledge the first sub-Saharan study of the quality of life with OAKHQOL Questionnaire in patients with knee osteoarthritis. The general characteristics of patients were similar to those of previous studies and other African studies [3] [6] [7] [20]. However, the average age (55 years) of our patients was lower than that of the cohort KHOALA in France (62 years); the body mass index was similar but with an average intensity of the largest pain in our series (55.5/100) than in the cohort KHOALA [21].

Static disorders of the knees (genu-flessum) and a high score Lequesne seem to be associated with significant impairment of the quality of life of patients. Similarly, it appears that the over 70 years of age has a significant impact on the "social activities" questionnaire OAKHQOL component. The social activity plays an important role in patients of this age group because of their status as resource persons in the African culture.

Table 4. Distribution of standardized questionnaire OAKHQOL according to patient characteristics scores.

\begin{tabular}{|c|c|c|c|c|c|}
\hline & $\begin{array}{l}\text { Physical Activity } \\
\left(\mathbf{p}^{*}\right)\end{array}$ & Mental Health (p) & Pain (p) & Social Support (p) & Social Activities (p) \\
\hline Age & $(0.0619)$ & $(0.0234)$ & $(0.0263)$ & (0.3390) & $(0.0006)$ \\
\hline $30-40$ & 54.5 & 49.5 & 58.7 & 61.3 & 59.7 \\
\hline $40-50$ & 70.3 & 69.4 & 70.9 & 76.5 & 87.3 \\
\hline $50-60$ & 62.1 & 63.8 & 58.5 & 78.6 & 78.3 \\
\hline $60-70$ & 58.5 & 66.7 & 54.3 & 76.2 & 70.7 \\
\hline$\geq 70$ & 59.0 & 78.3 & 57.2 & 70.8 & 59.2 \\
\hline Sex & $(0.6942)$ & $(0.6402)$ & $(0.5679)$ & $(0.9960)$ & $(0.4675)$ \\
\hline Male & 64.5 & 69.2 & 63.8 & 75.6 & 71.1 \\
\hline Female & 62.4 & 66.5 & 60.2 & 75.6 & 76.2 \\
\hline BMI & 0.8939 & (0.1438) & $(0.9439)$ & (0.7046) & $(0.0277)$ \\
\hline$<18$ & 64.7 & 80.8 & 62.5 & 80.0 & 31.7 \\
\hline $18-25$ & 65.6 & 74.5 & 64.3 & 70.2 & 80.9 \\
\hline $25-30$ & 61.7 & 67.2 & 62.2 & 77.6 & 72.0 \\
\hline$\geq 30$ & 61.5 & 62.2 & 60.5 & 76.0 & 78.7 \\
\hline Menopause & $(0.0114)$ & $(0.8958)$ & $(0.0096)$ & $(0.0314)$ & $(0.1221)$ \\
\hline Static Disorders & $(0.000)$ & $(0.000)$ & $(0.000)$ & $(0.000)$ & $(0.000)$ \\
\hline Genu Flessum & 50.7 & 45.2 & 20.0 & 73.1 & 50.0 \\
\hline Genu Varum & 54.2 & 61.5 & 46.7 & 75.0 & 68.3 \\
\hline Joint Limitation & $(0.0750)$ & $(0.0105)$ & $(0.0017)$ & (0.3115) & $(0.0010)$ \\
\hline Kellgren Classification (Stage 3) & $(0.3284)$ & $(0.5526)$ & $(0.6620)$ & $(0.2051)$ & $(0.3440)$ \\
\hline Lequesne Score (Severe) & $(0.000)$ & $(0.0086)$ & $(0.000)$ & $(0.7825)$ & $(0.0001)$ \\
\hline
\end{tabular}

p* probabilité. 
The normalized values of the different components were higher in our comparison to those of the French series [16], Spain [22] and Morocco [23] series. The quality of life of patients although reduced, seems better in our series than in those just mentioned. This could be different socio-cultural (greater acceptance of illness) or due to methodological biases. Business data, settings of origin, urban or rural, and living conditions are useful for the interpretation of quality of life scales. The recruitment of our patients was only done in consultation Rheumatology, thus excluding serious surgical consequent having a greater impairment of quality of life. In addition, the psychometric properties and the relevance of the questionnaire OAKHQOL in black African culture are not known. Indeed, we used the French version and it is obvious that some items do not match the black African cultural elements. It is therefore important that we develop a black African version. In addition, OAKHQOL questionnaire is a self-administered [17]. In our study, due to a significant rate of illiteracy, the questionnaire was administered to the patient; this could influence the answers. Further studies are needed with a questionnaire OAKHQOL “tropicalised” and self-administered.

\section{Conclusion}

Osteoarthritis of knee has an impact on the quality of life of patients treated in rheumatology consultation in Burkina Faso by OAKHQOL questionnaire. However, this questionnaire should be adapted to the cultural aspects of this part of the world to minimize the methodological biases that may have influenced our results and to understand the real impact of the disease. This would allow a more effective management.

\section{Conflict of Interest}

The authors declare no conflict of interest related to this work.

\section{References}

[1] Dillon, C.F., Rasch, E.K., Gu, Q. and Hirsch, R. (2006) Prevalence of Knee Osteoarthritis in the United States. Arthritis Data from the Third National Health and Nutrition Examination Survey 1991-1994. The Journal of Rheumatology, 33, 2271-2279.

[2] Lanes, S., Lanza, L., Radensky, P., Yood, R., Meenan, R., Walker, A., et al. (1997) Resource Utilization and Cost of Care for Rheumatoid Arthritis and Osteoarthritis in a Managed Care Setting: The Importance of Drug and Surgery Costs. Arthritis \& Rheumatism, 40, 1475-1481. http://dx.doi.org/10.1002/art.1780400816

[3] Avimadje, A.M., Pin, P., Addra, B., Djorolo, F., Guenou, A.D. and Houngbe, F. (2003) Topographic Distribution of Osteoarthritis. Synoviale, 123, 21-27.

[4] Bileckot, R., Nstiba, H. and Ognami, J.B. (1992) Clinical and Etiological Aspects of Knee Osteoarthritis in the Congo. Révue du rhumatisme et des maladies ostéoarticulaires, 59, 683-684.

[5] Ebong, W.E. (1985) Osteoarthritis of the Knee in Nigerians. Annals of the Rheumatic Diseases, 44, 682-684. http://dx.doi.org/10.1136/ard.44.10.682

[6] Eti, E., Kouakou, H.B., Daboiko, J.C., Ouali, B., Ouattara, B., Gabla, K.A., et al. (1998) Epidemiology and Features of Knee Osteoarthritis in the Ivory Coast. Revue du Rhumatisme, 65, 766-770.

[7] Mijiyawa, M. and Ekoue, K. (1993) Osteoarthritis of Limbs in Hospital Practice in Lomé (Togo). Revue du Rhumatisme, 60, 514-517.

[8] Ouedraogo, D.D., Ntsiba, H., Tiendrébéogo Zabsonré, J., Tieno, H., Bokossa, L.I.F., Kaboré, F. and Drabo, J. (2014) Clinical Spectrum of Rheumatologic Diseases in a Department of Rheumatology in Ouagadougou (Burkina Faso). Clinical Rheumatology, 33, 385-389. http://dx.doi.org/10.1007/s10067-013-2455-4

[9] Fautrel, B., Hilliquin, P., Rozenberg, S., Allaert, F.A., Coste, P., Leclerc, A., et al. (2005) Impact of Osteoarthritis: Results of a Nationwide Survey of 10,000 Patients Consulting for OA. Joint Bone Spine, 72, 404-410. http://dx.doi.org/10.1016/j.jbspin.2004.08.009

[10] Lequesne, M., Lamotte, J. and Samson, M. (1993) Indices of Quality of Life and the Algo-Functional Indices in Osteoarthritis. Revue du Rhumatisme, 60, 23s-29s.

[11] Bellamy, N., Buchanan, W.W., Goldsmith, C.H., Campbell, J. and Stitt, L.W. (1988) Validation Study of WOMAC: A Health Status Instrument for Measuring Clinically Significant Patient Outcomes Relating to Antirheumatic Drug Therapy in Patients with Osteoarthritis of the Hip or Knee. Journal of Rheumatology, 15, 1833-1840.

[12] Merle-Vincent, F., Couris, C.M., Schott, A.M., Perier, M., Conrozier, S., Conrozier, T., et al. (2007) Cross-Sectional Study of Pain and Disability at Knee Replacement Surgery for Osteoarthritis in 299 Patients. Joint Bone Spine, 74, 
612-616. http://dx.doi.org/10.1016/j.jbspin.2007.01.038

[13] Pouchot, J., Guillemin, F., Coste, J., Bregeon, C. and Sany, J. (1996) Validity, Reliability and Sensitivity to Change of a French Version of the Arthritis Impact of Measurement Scales 2 (AIMS2) in Patients with Rheumatoid Arthritis Treated with Methotrexate. Journal of Rheumatology, 23, 52-60.

[14] Guillemin, F., Coste, J., Pouchot, J., Ghezail, M., Bregeon, C. and Sany, J. (1997) The AIMS2-SF: A Short Form of the Arthritis Impact Measurement Scales 2. French Quality of Life in Rheumatology Group. Arthritis and Rheumatology, 40, 1267-1274.

[15] Rat, A.C., Baumann, C., Klein, S., Loeuille, D. and Guillemin, F. (2008) Effect of Order of Presentation of a Generic and a Specific Health-Related Quality of Life Instrument in Knee and Hip Osteoarthritis: A Randomized Study. Osteoarthritis and Cartilage, 16, 429-435. http://dx.doi.org/10.1016/j.joca.2007.07.011

[16] Rat, A.C., Pouchot, J., Coste, J., Baumann, C., Spitz, E., Retel-Rude, N., Baumann, M., Le Quintrec, J.S., DumontFischer, D. and Guillemin, F., Quality of Life in Rheumatology Group (2006) Development and Testing of a Specific Quality-of-Life Questionnaires for Knee and Hip Osteoarthritis: OAKHQOL (OsteoArthritis of Knee Hip Quality of Life). Joint Bone Spine, 73, 697-704. http://dx.doi.org/10.1016/j.jbspin.2006.01.027

[17] Rat, A.C., Coste, J., Pouchot, J., Baumann, M., Spitz, E., Retel-Rude, N., Le Quintrec, J.S., Dumont-Fischer, D. and Guillemin, F. (2005) OAKHQOL: A New Instrument to Measure Quality of Life in Knee and Hip Osteoarthritis. Journal of Clinical Epidemiology, 58, 47-55. http://dx.doi.org/10.1016/j.jclinepi.2004.04.011

[18] Felson, D.T. (1990) The Epidemiology of Knee Osteoarthritis: Results from the Framingham Osteoarthritis Study. Seminars in Arthritis and Rheumatism, 20, 42-50. http://dx.doi.org/10.1016/0049-0172(90)90046-I

[19] Altam, R., Alarcon, G., Appelrouth, D., Bloch, D., Borenstein, D., Brandt, K., et al. (1991) The American Colleague of Rheumatology Criteria for the Classification and Reporting of Osteoarthritis of the Hip. Arthritis \& Rheumatism, 34, 505-514. http://dx.doi.org/10.1002/art.1780340502

[20] Ouedraogo, D.D., Séogo, H., Cissé, R., Tieno, H., Ouedraogo, T., Nacoulma, I.S. and Drabo, Y.J. (2008) Risk Factors Associated with Osteoarthitis of the Knee in a Rheumatology Outpatient Clinic in Ouagadougou (Burkina Faso). Médecine Tropicale, 68, 597-599.

[21] Guillemin, F., Rat, A.C., Roux, C.H., Fautrel, B., Mazieres, B., Chevalier, X., Euller-Ziegler, L., Fardellone, P., Lock, E., Morvan, J., Pouchot, J., Coste, J. and Saraux, A., KHOALA Cohort Study (2012) The KHOALA Cohort of Knee and Hip Osteoarthritis in France. Joint Bone Spine, 79, 597-603. http://dx.doi.org/10.1016/j.jbspin.2012.03.011

[22] Gonzalez Sáenz de Tejada, M., Escobar, A., Herdman, M., Herrera, C., García, L. and Sarasqueta, C. (2011) Adaptation and Validation of the Osteoarthritis Knee and Hip Quality of Life (OAKHQOL) Questionnaire for Use in Patients with Osteoarthritis in Spain. Clinical Rheumatology, 30, 1563-1575. http://dx.doi.org/10.1007/s10067-011-1855-6

[23] Serhier, Z., Harzy, T., ELfakir, S., Diouny, S., El Rhazi, K., Bennani Othmani, M., Salmi, L.R. and Nejjari, C. (2012) Cross-Cultural Adaptation and Validation of the Knee and Hip Health-Related Quality of Life (OAKHQoL) in a Moroccan Arabic-Speaking Population. Rheumatology International, 32, 1015-1023. http://dx.doi.org/10.1007/s00296-010-1781-y 
Scientific Research Publishing (SCIRP) is one of the largest Open Access journal publishers. It is currently publishing more than 200 open access, online, peer-reviewed journals covering a wide range of academic disciplines. SCIRP serves the worldwide academic communities and contributes to the progress and application of science with its publication.

Other selected journals from SCIRP are listed as below. Submit your manuscript to us via either submit@scirp.org or Online Submission Portal.
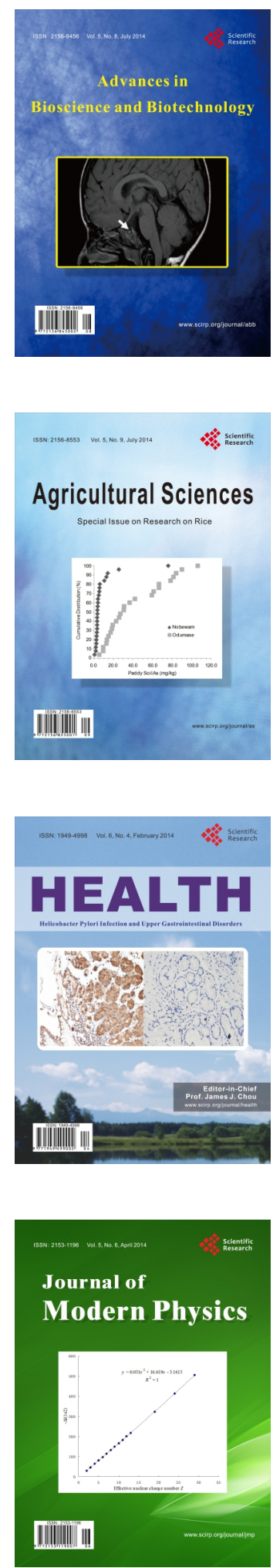
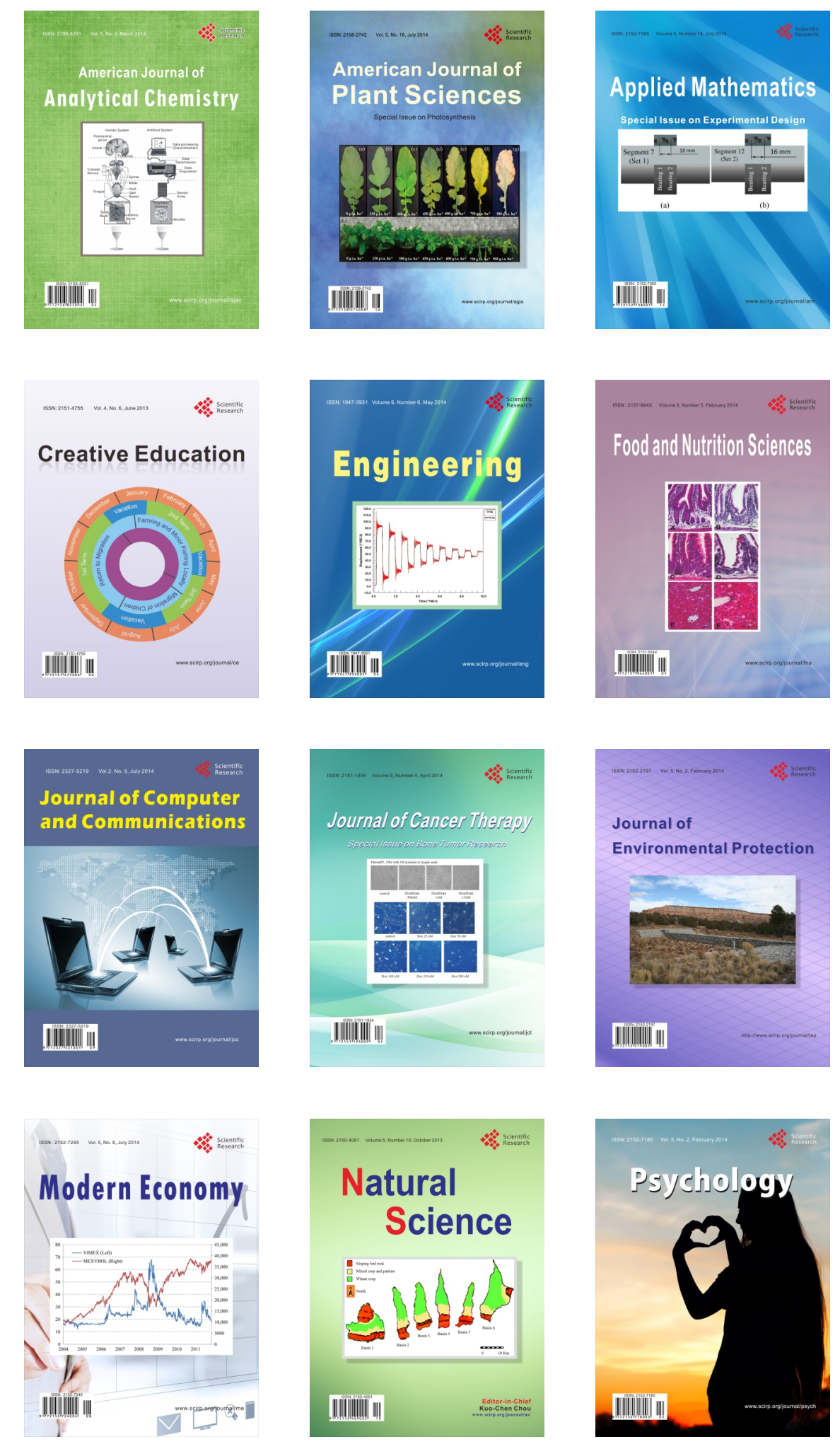